\title{
IC Engine Performance Using Ceramic Coated Piston
}

\author{
Ravi S Modi ${ }^{1}$, Prof.Maulik A Modi ${ }^{2}$ \\ ${ }^{1}$ ME Scholar, Mechanical Department, LDRP-ITR, Gandhinagar, India \\ ${ }^{2}$ Assistant Professor, Mechanical Department, LDRP-ITR, Gandhinagar, India
}

\begin{abstract}
Internalcombustionengineconvertpotentialchemical energy in the form of heat derived from a fuelintomechanical energy. Probability $31 \%$ of theenergy removed inanICengineis transform into work. The reaming energy is lacking in the formofheatandfrictionintheengine. Engine componentsaredesigned to convert energy in an ICengine for maximum efficiency. Material used forenginecomponents must withstand heat and stress created inside the engine during operation, and meet sizeandweight requirements. Engine componentscommonlyrequired in reciprocating engines include the block of engine, cylinder head, crankshaft, piston and pistonrings,connectingrod,bearings,flywheel,andvalvetrain. The constantly increasing fuel prizes one of the main improvement directions in the vehicle industry is to increase the combustion efficiency. My aim is to reducethe fuel consumption but to require the same performance. The biggestparts of the energy removeon combustion chamber transfer to its environment by thermal waste instead of power train. In order to reducethe thermal waste in future engineswe need to use ceramic as coating layer on aluminum alloy piston. In this study, investigating of IC engine performance by using conventional (uncoated) piston and ceramic coated piston.
\end{abstract}

Keywords: Petrol engine, Thermal Barrier, Piston Coating, Performance, Exhaust emission.

\section{Introduction}

Automobile parts are in great demand these days because of increased use of automobiles. The biggestusedrives of automobiles, prime movers, machine of agricultural, ships, motorbike are still the IC piston engines. The increased demand is requiring to improved pursuance and decrease cost of these components. R\&D and testing engineers should develop critical components in shortest possible time to minimize launch time for new products. This necessitates understanding of new technologies and quick absorption in the development of new products [1]. Thus automotive industry spends lots of months and property to develop IC engines. Here are two main ways to increase power: decreasing the emissions of harmful gases and improve the efficiency. Thermal fatigue is depended produce the stresses on the material which is achieved by temperature gradients in the engine component. Thermal stresses are tough to reduce because here are two types of thermal stressesin a piston (a) Stresses for the vertical temperature distribution along the piston - higher temperature at the above and lower temperature at the bottom. [5]. (b) Stresses for the various temperature at the head of the piston due to the hot gases or to fuel infringement (which is relate with higher injection pressure) [5]. Damage and broken parts are so expensive to replace and generally are not easily available. So to avoid this problem it needs design of a new part, copy of an existing part, recovery of a damaged or broken part, improvement of model precision and inspection of numerical model [8].

\section{Principle Related The Piston}

The piston has an important function of the driving chain. Its main requirement to lock one side of cylinder of the IC engine, to develop the changing volume, required for engine working. Here thermal energy that come for liberated at a flame of the fuel, spark with the ignition plug converts into mechanical work as the piston moves. The gas energy produces effect on the sideof the piston and makes it move on a straight line. Some backup move come at starting and converts into turning action for the crankshaft. [2,3] The energy coming from the gas-pressure depends on the diameter of the block of cylinder and the maximum pressure of burning gas, but the foundation of the piston is the piston pin. Depend on the at this moment angle of the crankshaft, here comeback energy moves the piston on the inside surface of the cylinder. Reaching the departed point, it novelty the surface to the other side. In the checked out point, the pinning become explosive, the piston is comfortable to make absolutely size displacement, as far as the energy come into starting that press it on the surface. This process makes unwanted crash and vibration when the engine works. The surface alternating appears ahead the piston reaches the dead point. [6]

During working of the IC engine, here piston is extremely taxed not just mechanically but thermal stress as well. On the area of the burning area, it is touched directly with hot gas, and the flame front. On the piston, maximum thermal stress is heat transfer, and just partly heat radiation. The thermal stress is alternatively change because of the fast movable of the working area, So the temperature of the upper surface of the piston can change, when the intake it is the lowest, and during the exhausting it is the biggest. [4] In the intake 
stroke,fresh mixture streams come into the burning area, and then it is sparked by the spark plug. By the explosion thermal energy comes at starting, which pushes the piston down. For us, it would be the best solution if the work coming from the temperature would take only effect on the driving of the vehicle. If engineer could create such an engine, its efficiency would be $100 \%$, but it cannot be made in the practice.

The temperature gets from a flame of mixture, useful for works only in one by third part even in the best engine, the second one of third part is absorb by the burn out fumes, and remaining third part energy gets lost for cooling. In most of the case, two by third part of the combustion temperature used for cooling gets completed the engine cylinder head with heat transferring and conducting into the environment, one third part through the crown of the piston coming the crankcase. My work with the development is to reduce stress concentration, reduce the leaving heat and increase the efficiency of the engine.

\section{Materials And Methods}

The internal engine rejects about two by thirds of the heat energy of the fuel, one by third to coolant and one third to the burn out, so only one third of energy is transfer into useful work. Thermal barrier coating in internal engine leads to advantages including huge power densityreduces the transient stress and stress due to thermal in the parts, reduced specific fuel consumption, increase effective efficiency and thermal efficiency andthe rate of vaporization is increase and the better mixing of the fuel due to higher combustion chamber temperature.

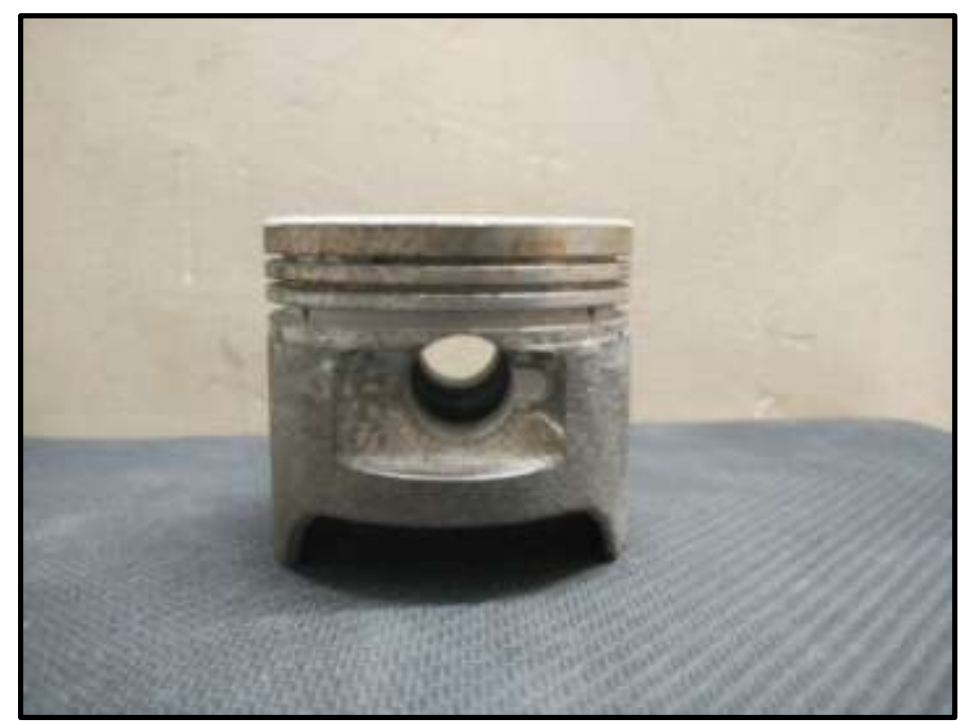

Fig. 1:Ceramic coated piston

In the today world work, a Thermal Barrier Coating was deposited on the topsurface of the piston to increase the performance characteristics of IC engine. The outer area of the top surface of the piston was coated with ceramic material, alumina (which hasa low conductivity). The thermal barrier coating process relies on the chemical reaction between oxygen and a fuel of combustion (acetylene, hydrogen) to produce a heat generates. This heat source produces a gas stream. Alumina as a feed stock material sprayed into the flame form of a powder, and compressed air is then used to atomize the molted metal and accelerate particle onto the piston surface as shown in fig. 1 . The thickness of the coating surface is $2 \mathrm{~mm}$.

\section{Experimental Setup}

The main aim of the experimentation is to check the chain reaction of variation load on IC engine performance and emission characteristics of S.I. Engine. The experimental work under this project include of two parts, initial experimental work to analyze the reaction of different load on engine performance and emission using convention (uncoated) piston made of aluminum alloy in second phase, optimizing work for ceramic coated piston. Initial experimental work includes preparation of experiment setup, we use thermal barrier coating process on piston and measurement of various engine parameters and emission parameters by running the engine on different load. This experimental work, we can vary different load among their respective range. The measuring parameters are Brake Power, Brake Specific Fuel Consumption, Brake Thermal Efficiency, exhaust gas temperature and emission characteristics i.e. Carbon Monoxide, Hydrocarbons, Nitrogen Oxide. Temperature at the exhaust outlet was monitored using thermocouple. A single cylinder four stroke petrol engine is taken for the experimentation. The experimental engine is connected to a rope brake dynamometer by a load cell. The schematic layout of the experimental set up is shown in below figure 2 . 


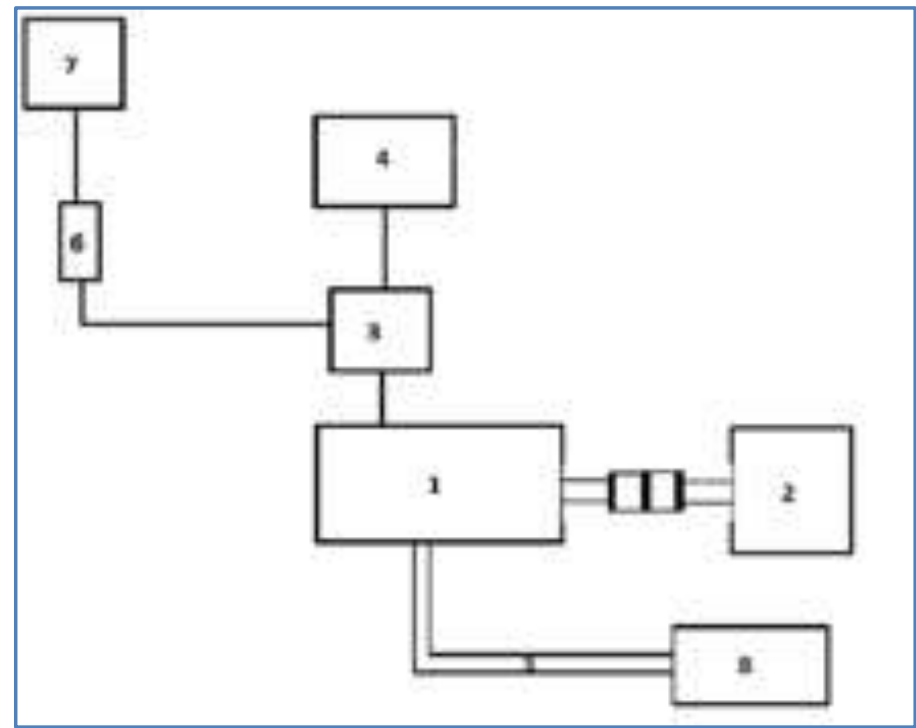

Fig. 2: Line Diagram of the Experimental Setup

List of the experimental setup components

1. Engine

2. Dynamometer

3. Carburetor

4. Air filter

5. Exhaust pipe

6. Burette

7. Fuel tank

8. Exhaust gas analyzer

Table 1:Engine Specification

\begin{tabular}{|l|l|}
\hline Parameters & Values \\
\hline Engine type & Four stroke petrol engine \\
\hline Induction & Air cooled type \\
\hline No. of cylinder & Single cylinder \\
\hline Displacement & $97.2 \mathrm{cc}$ \\
\hline Max. Power & $5.50 \mathrm{KW}$ \\
\hline Rated speed & $8000 \mathrm{rpm}$ \\
\hline Compression Ratio & $9.0: 1$ \\
\hline Starting & Kick start \\
\hline Bore & $50 \mathrm{~mm}$ \\
\hline Stroke & $49.5 \mathrm{~mm}$ \\
\hline
\end{tabular}

A single cylinder four stroke petrol engine is used to conduct experiments. Their designations are given in Table. Concentrations of the $\mathrm{CO}$ and unburned $\mathrm{HC}$ are measured using exhaust gas analyzer. Exhaust gas temperature are measured by using thermocouple.

V. Result Table

Table 2: Result table for the Conventional Piston

\begin{tabular}{|c|c|c|c|c|c|}
\hline Sr. No. & $\begin{array}{c}\text { Load } \\
(\mathbf{k g})\end{array}$ & $\begin{array}{c}\text { Torque } \\
(\mathbf{N m})\end{array}$ & $\begin{array}{c}\mathbf{B P} \\
(\mathbf{k W})\end{array}$ & $\begin{array}{c}\boldsymbol{\eta}_{\text {bte }} \\
(\boldsymbol{\%})\end{array}$ & $\begin{array}{c}\text { BSFC } \\
(\mathbf{k g} / \mathbf{k W h})\end{array}$ \\
\hline 1 & 1 & 1.38 & 0.12 & 2 & 4.0 \\
\hline 2 & 2 & 2.77 & 0.14 & 2.2 & 3.8 \\
\hline 3 & 3 & 4.14 & 0.17 & 3.0 & 2.5 \\
\hline 4 & 4 & 5.53 & 0.21 & 4.75 & 2.0 \\
\hline 5 & 5 & 6.91 & 0.23 & 5.0 & 1.5 \\
\hline 6 & 6 & 8.30 & 0.25 & 7.5 & 1.0 \\
\hline 7 & 7 & 9.68 & 0.28 & 10.71 & 0.7 \\
\hline 8 & 8 & 11.07 & 0.30 & 15.0 & 0.5 \\
\hline
\end{tabular}


Table 3: Result table for the Ceramic Coated piston

\begin{tabular}{|c|c|c|c|c|c|}
\hline Sr. No. & Load (kg) & $\begin{array}{c}\text { Torque } \\
(\mathbf{N m})\end{array}$ & $\begin{array}{c}\text { BP } \\
(\mathbf{k W})\end{array}$ & $\begin{array}{c}\boldsymbol{\eta}_{\text {bte }} \\
(\mathbf{\%})\end{array}$ & $\begin{array}{c}\text { BSFC } \\
(\mathbf{k g} / \mathbf{k W h})\end{array}$ \\
\hline 1 & 1 & 1.38 & 0.13 & 2.26 & 3.30 \\
\hline 2 & 2 & 2.77 & 0.15 & 2.50 & 3.00 \\
\hline 3 & 3 & 4.14 & 0.17 & 3.57 & 2.10 \\
\hline 4 & 4 & 5.53 & 0.23 & 4.69 & 1.80 \\
\hline 5 & 5 & 6.91 & 0.26 & 5.24 & 1.43 \\
\hline 6 & 6 & 8.30 & 0.28 & 4.42 & 0.68 \\
\hline 7 & 7 & 9.68 & 0.31 & 12.03 & 0.56 \\
\hline 8 & 8 & 11.07 & 0.32 & 16.39 & \\
\hline
\end{tabular}

\section{Result And Discussion}

\subsection{Fuel consumption}

Figure 3 shows fuel consumption for different loading condition. From this graph it is conclude that the fuel consumption is decrease with increase of load for normal piston and coated piston. Fuel consumption is lower for coated piston as compare to uncoated piston.

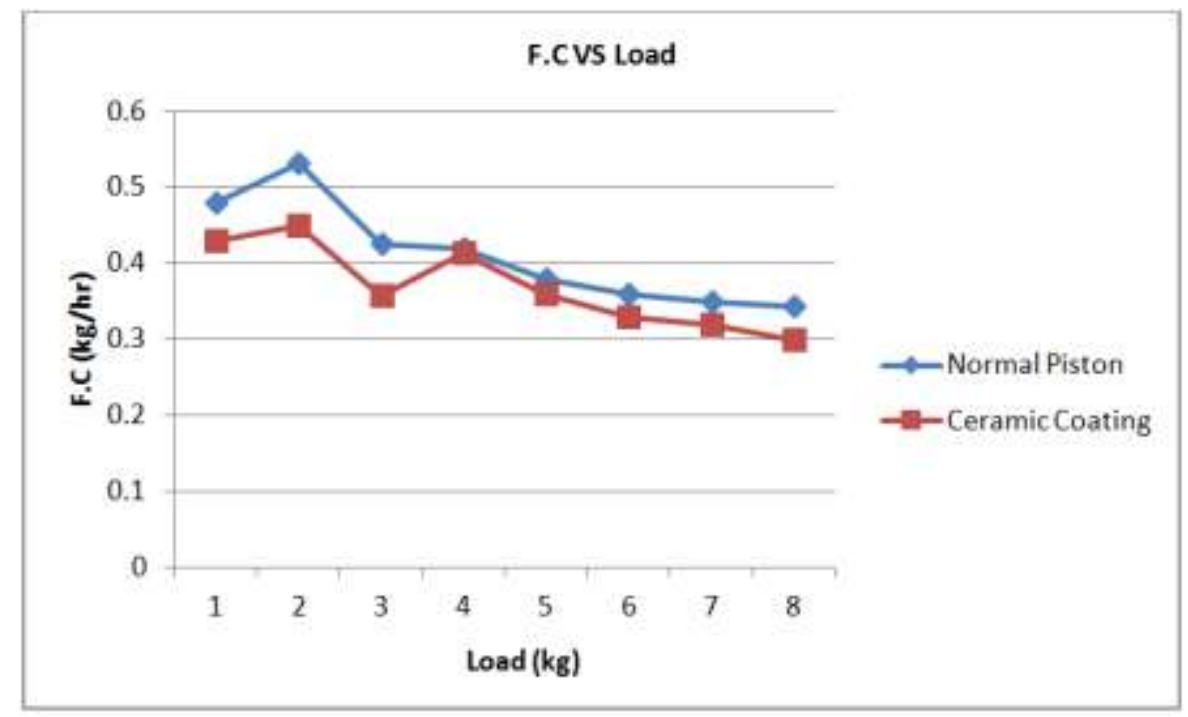

Fig. 3:Fuel Consumption v/s Load

\subsection{Brake Specific fuel consumption}

Figure 4 shows the variation of brake specific fuel consumption for different loading condition. Figure shows that brake specific fuel consumption for different loading condition. Brake specific fuel consumption is lower for ceramic coated piston compare to without coated piston.

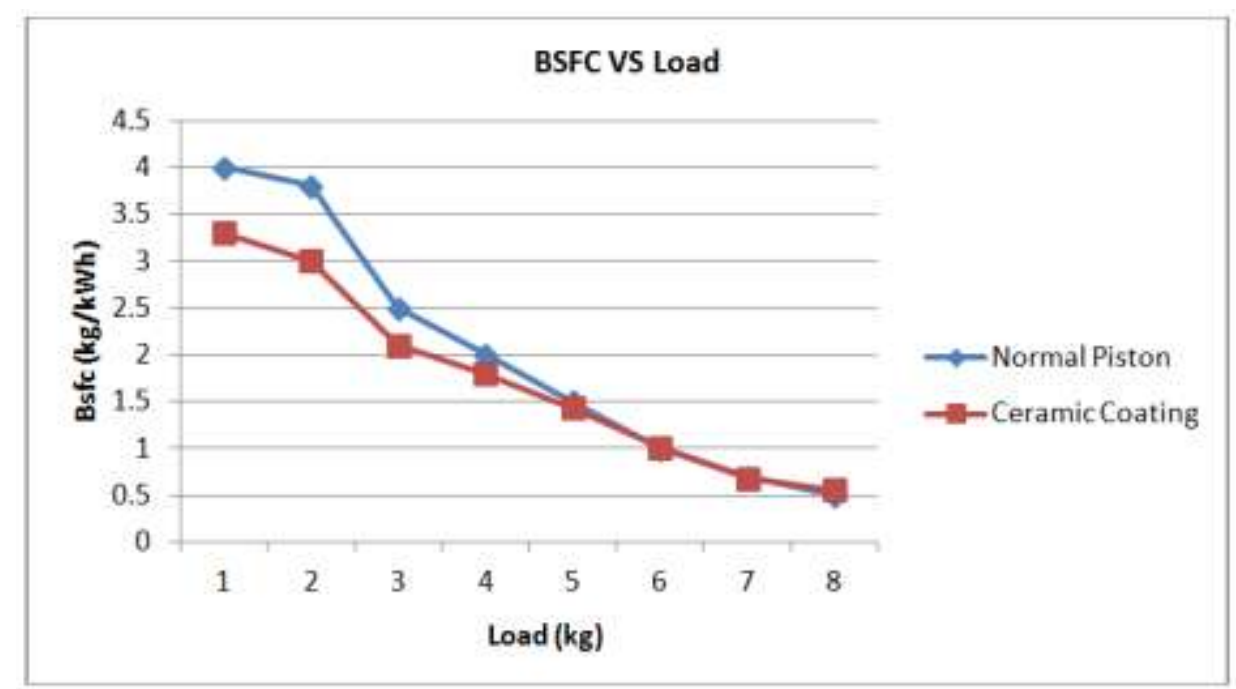

Fig. 4:Brake Specific fuel consumption vs. load 


\subsection{Brake power}

Figure 5 shows the variations of the brake power for different loads conditions. From the graph it is clear that the brake power increase with increase of load condition. Brake power is higher for coated piston as compare to without coated piston.

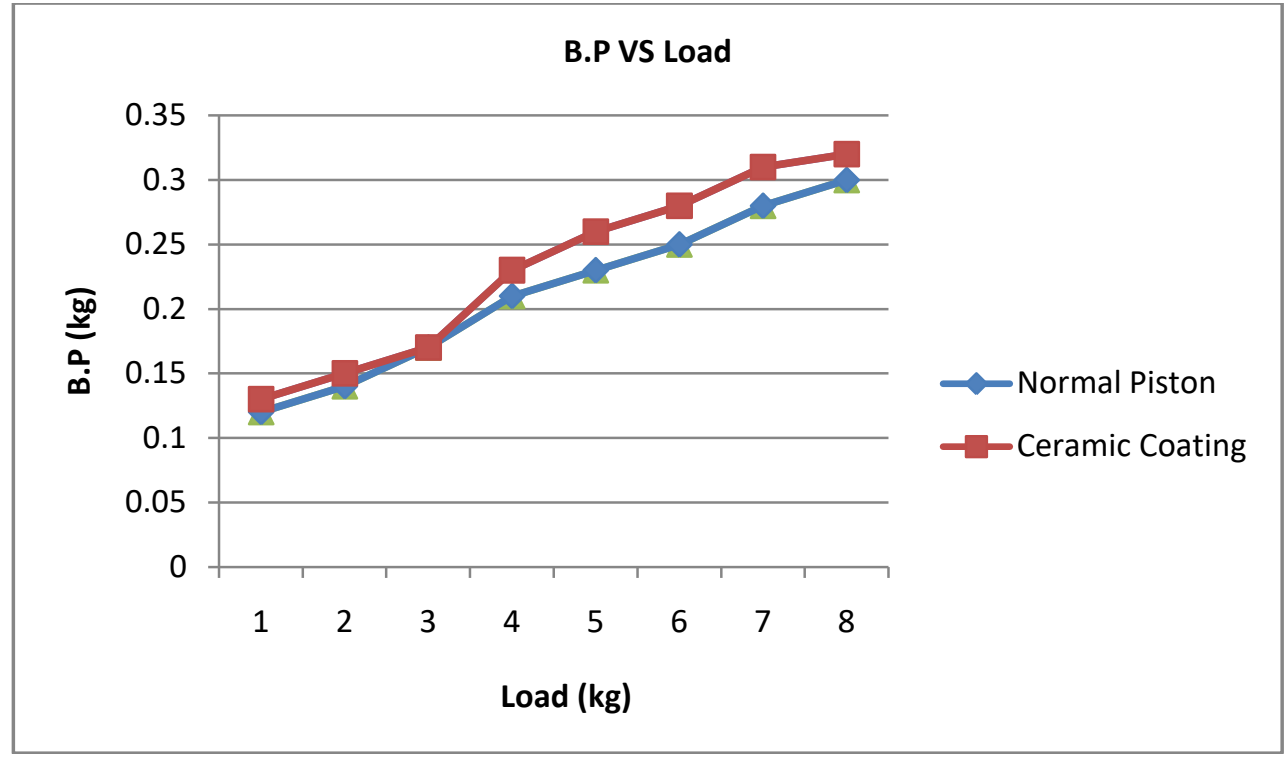

Fig. 5:Brake Power v/s Load

\subsection{Brake thermal efficiency}

The variations of brake thermal efficiency with Load for both cases are shown in figure 6. Brake thermal efficiency is defined as the ratio of brake power to product of fuel consumption and calorific value. Brake thermal efficiency for all the fuels increases as the load increase. The brake thermal efficiency increase for ceramic coated piston compare to the without coated piston.

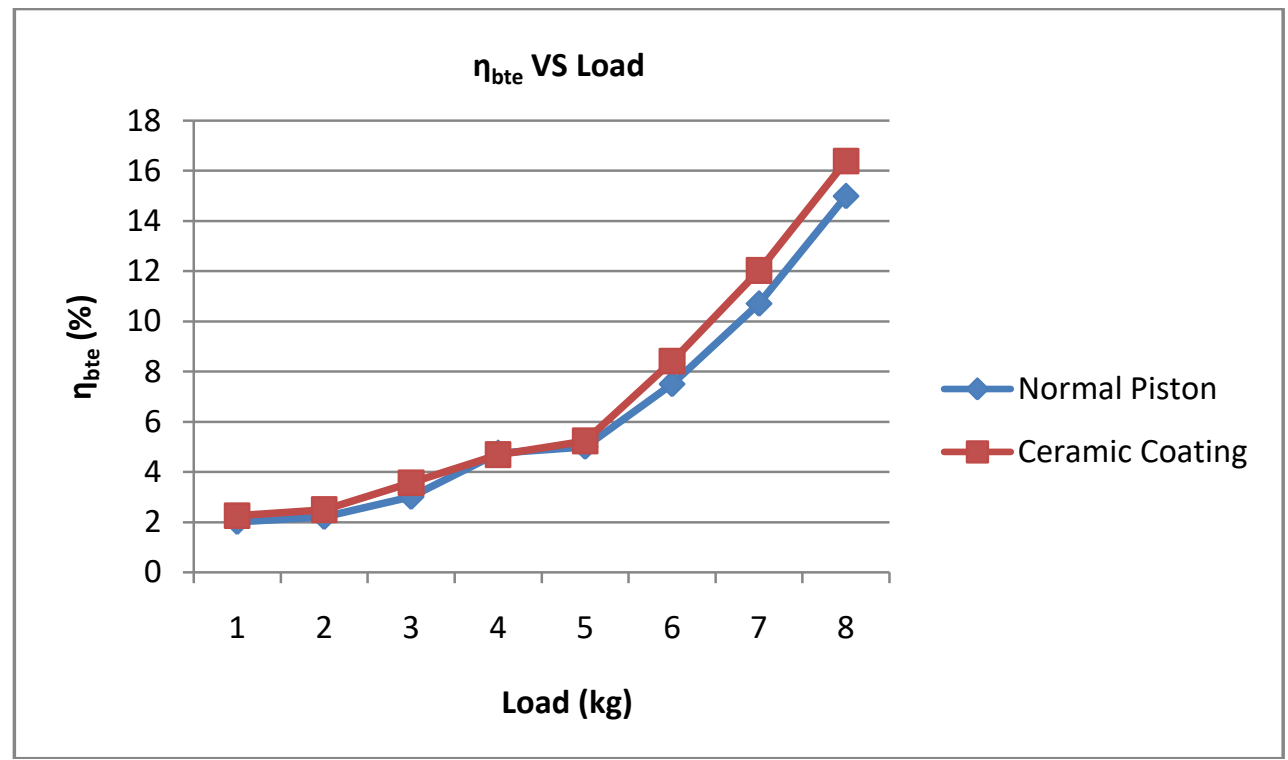

Fig. 6:Brake thermal efficiency v/s Load

\subsection{Carbon monoxide (CO) emission}

Figure 7 shows the variation of Carbon Monoxide (CO) with Load at various Oxygen admission levels. The main reason of generation of $\mathrm{CO}$ emission is in complete combustion and it is generally due to in sufficient availability of oxygen. 


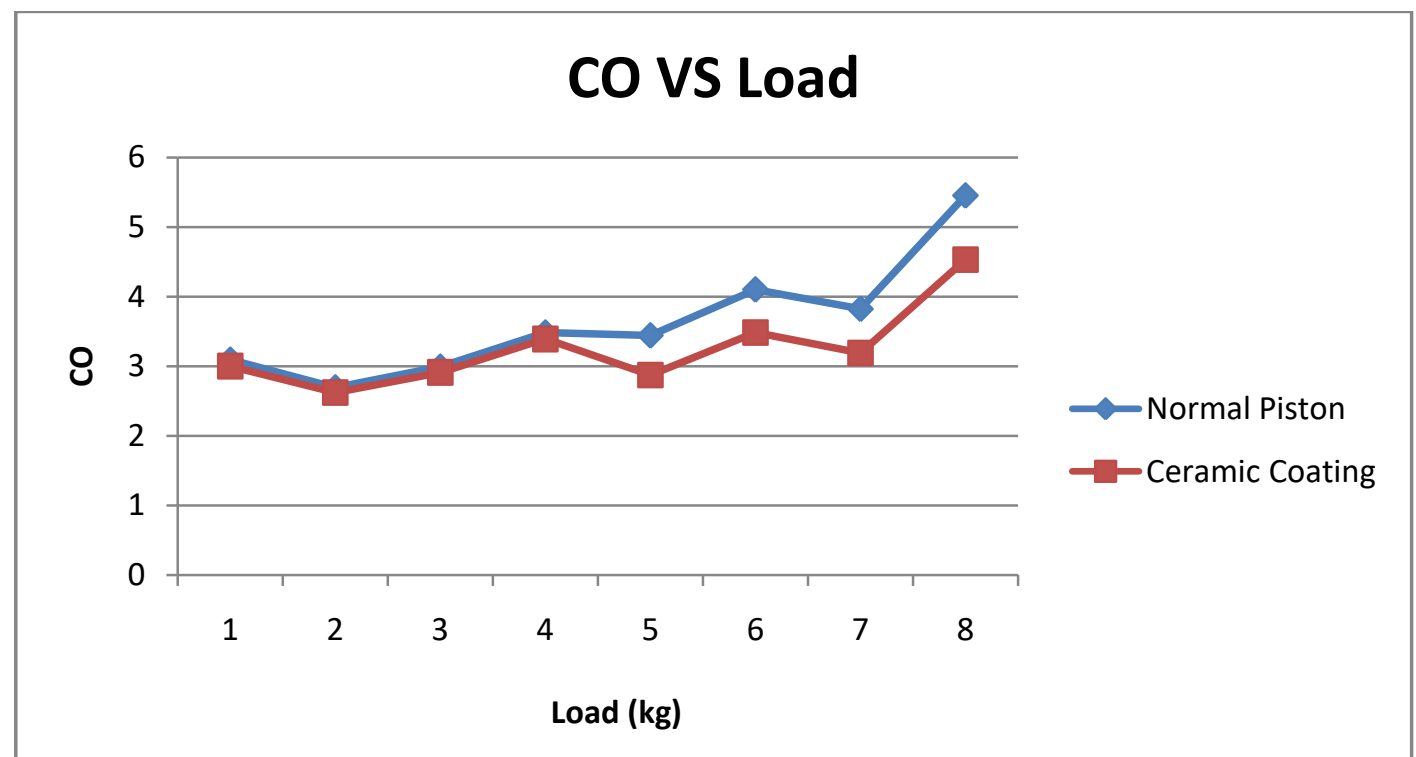

Fig. 7: Effect of Different Water content on Carbon Monoxide Emission

From above graph it is clear that the normal piston has highest percentage of CO emissions. At low load normal piston and coated piston has equal emissions of CO. Ceramic coated piston has very low production of CO than the normal piston.

\subsection{Hydrocarbon (HC) emission}

Figure 8 shows the variation of HC emission for different loading conditions. The hydro carbon reacts with air to produce smog. This may reduce visibility. In conventional internal combustion engine, the hydrocarbon fuel burns inside the engine in presence air. The amount of hydrocarbon fuel, which is not taking part in combustion process, is likely to come out as unburned hydrocarbon. There is normally some region within combustion chamber of an engine fueled with mixture where mixture is either too lean or too rich ignite. From above graph it is clear that the ceramic coated piston produces low amount of HC at high loads than the normal piston.

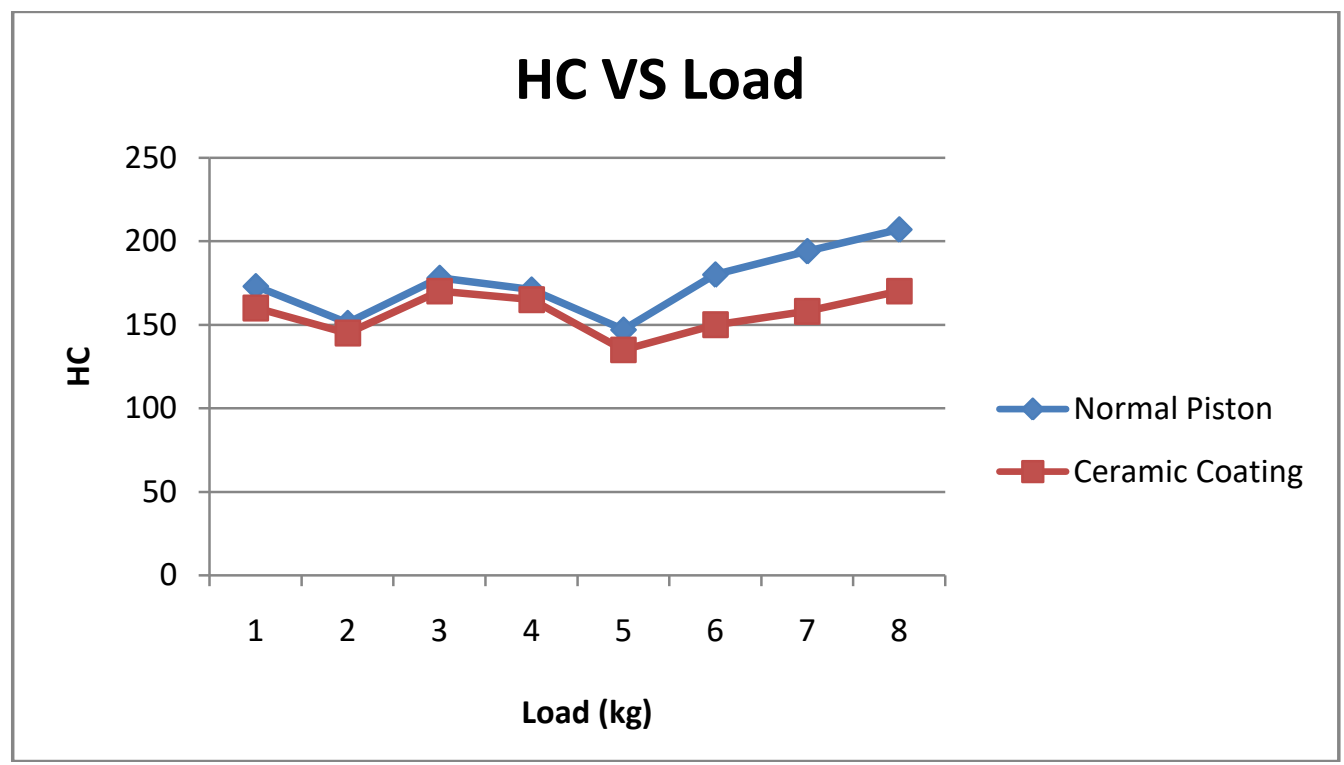

Fig. 8: hydrocarbons Emission for different fuels.

\subsection{Carbon dioxide emission}

Figure 9 shows the variation of Carbon dioxide $\left(\mathrm{CO}_{2}\right)$ with Load. The generation of $\mathrm{CO}_{2}$ emission is incomplete combustion and it is generally due to insufficient availability of oxygen. The graph shows that the $\mathrm{CO}_{2}$ emission 


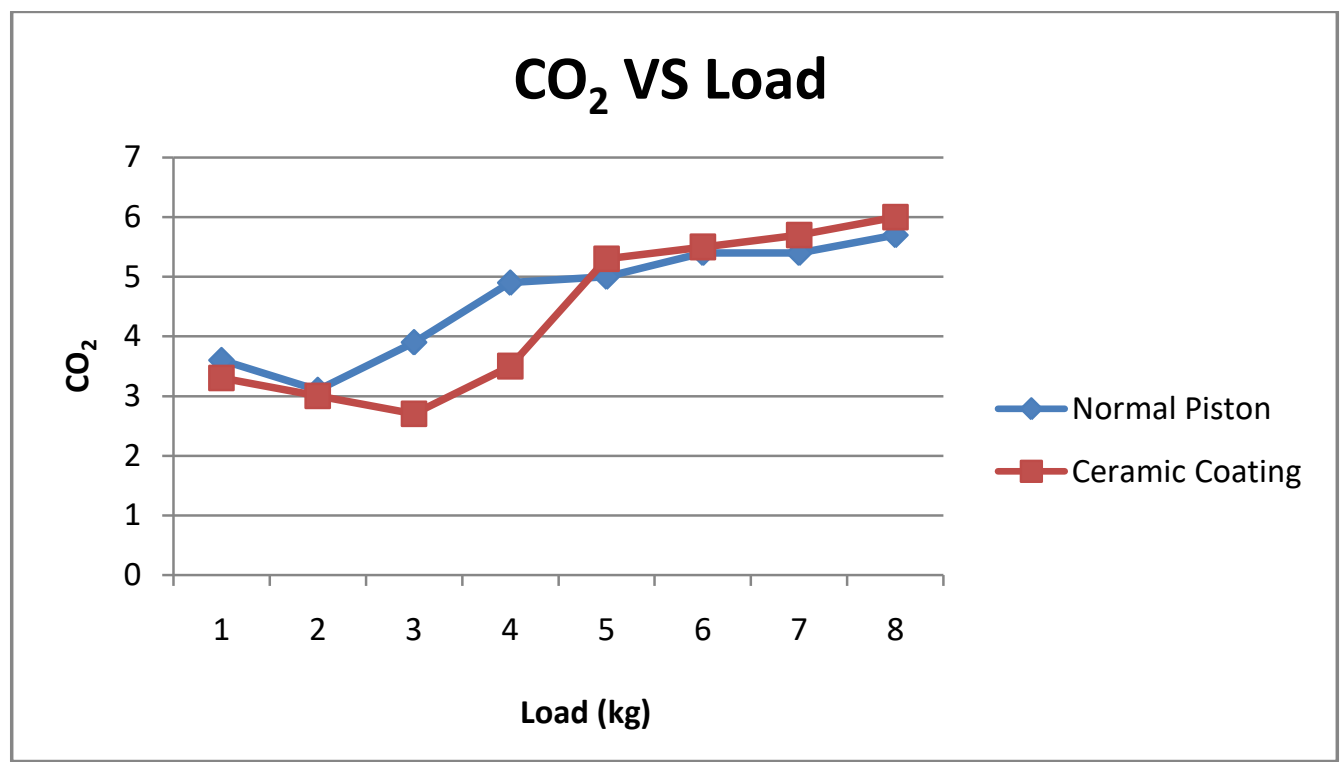

Fig. 9: Carbon Dioxide Emission for different fuels

From this graph it is clear that at very low load the coated piston has low production of $\mathrm{CO}_{2}$ than normal piston. As load increases the production of $\mathrm{CO}_{2}$ increases. But at high load the normal piston has lowest production.

\section{Conclusion}

The mass of fuel consumption is decreased $4.12 \%$ by providing ceramic coating on piston compare to non-coated piston. The brake thermal efficiency is increased by $12 \%$ by providing ceramic coating on piston compare to non-coated piston. The brake specific fuel consumption is decreased $2.65 \%$ by providing ceramic coating on piston compare to non-coated piston. Emission of carbon \& hydrocarbon in the exhaust gases is reduced by providing ceramic coating on piston compare to non-coated piston.

The performance of an IC engine is improved with ceramic Thermal Barrier Coating, as compared to normal piston. Therefore, ceramic Thermal Barrier Coating is an effective method to enhance performance of SI Engine. The engine with TBC piston helps in increasing the power of the engine as stated above. This is because complete combustion of the charge in the combustion chamber which leads to minimization of emission of carbon \& hydrocarbon in the exhaust gases.

\section{Acknowledgements}

I am very thankful to all those who helped me for the successful completion of the literature review and for providing valuable guidance throughout the semester. I would like to thank Assistant Professor Maulik A Modi, Professor Dr. Tushar M Patel and our department of mechanical engineering, LDRP - ITR, Gandhinagar. Their constant support, encouragement, and constructive criticism have been invaluable assets through my research work.

\section{References}

[1] C.Gang, H. Yuejun, S. Peizhi" Research actualities on materials and processes of engine piston and cylinder liner," in Volume 14 on Materials Science and Engineering of Powder Metallurgy, Changsha, China, 2009, pp.205-213

[2] Gudimetal P, Gopinath C.V, "Finite Element analysis of Reverse Engineered Internal Combustion Engine Piston", AIJSTPME (2009) 2(4):85-92.

[3] A.Atish Gawale, A. Shaikh and Vinay Patil, "Nonlinear Static Finite Element Analysis and Optimization of connecting rod World Journal of Science and Technology, Vol. 2(4),2012.

[4] Ch.Venkata Rajam, P.V.K.Murthy, M.V.S.Murali Krishna, G.M.Prasada Rao "Design Analysis and Optimization of Piston using CATIA and ANSYS" January 2013, issue 2 volume 1IJIRES

[5] F.S. Silva "Fatigue on engine pistons - A compendium of case studies" Engineering Failure Analysis 13 (2006) 480-492 ELSEVIER

[6] Srecko Manasijevic, Wenping Zhang, Yibin Guo, Tao He, Dequan Zou "Thermal analysis on piston of marine diesel engine" Applied Thermal Engineering 50 (2013) 168e176 19 June 2012 ELSEVIER 
[7] Deovrat Vibhandik, Ameya Pradhan, Sampada Mhaskar, Nikita Sukthankar, Atul Dhale "Design Analysis and Optimization of Piston and Determination of its Thermal Stressesm Using CAE Tools" IJESRT [375-381] may2014

[8] Dániel Vaczkó "Piston development of a microconsumption race car" International Conference on Manufacturing Engineering and Materials, ICMEM , 2016 